\title{
Classification OF END-USE INDUSTRIAL Applications OF AdDitive ManUfacturing
}

\author{
Sergei Chekurov, Niklas Kretzschmar
}
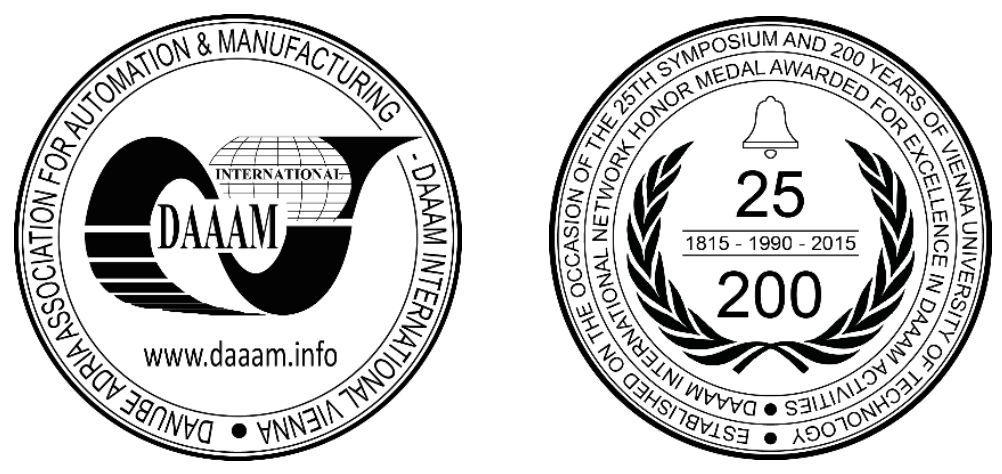

This Publication has to be referred as: Chekurov, S[ergei] \& Kretzschmar, N[iklas] (2018). Classification of End-Use Industrial Applications of Additive Manufacturing, Proceedings of the 29th DAAAM International Symposium, pp.08940900, B. Katalinic (Ed.), Published by DAAAM International, ISBN 978-3-902734-20-4, ISSN 1726-9679, Vienna, Austria

DOI: $10.2507 / 29$ th.daaam.proceedings.129

\begin{abstract}
Additive manufacturing (AM) has recently been gaining traction in the manufacturing of industrial end-use components and has found success in a variety of applications, which have varied from the production of superior high value components to the reduction of costs associated with procuring simple products, such as spare parts for consumer electronics. This spectrum of applications is causing confusion for companies who are willing to adapt AM in their operations and slowing down the rate of propagation of AM in industrial settings.

This paper attempts to clarify the opportunities of AM in end-use components by proposing a categorization system from the point of view of Design for Additive Manufacturing (DfAM). The categories are obtained from the existing DfAM literature and are "Components designed for AM", "Components redesigned for AM", and "Components not designed for AM". The article presents the categories in detail, explains when they should be used, and provides examples for each category.
\end{abstract}

Keywords: design for additive manufacturing; 3D printing; end-use additive manufacturing; rapid manufacturing; classification

\section{Introduction}

During the early years of the millennium, additive manufacturing (AM) had gained enough ground that the technology started to attract practitioners from a variety of fields, opening the technology to a vast array of applications from architectural prototyping to injection mold production [1], [2], [3]. The amount of uncategorised information regarding the applications of AM was understandably overwhelming to new practitioners and a need for classifying them was recognized. Subsequently, the applications of AM were divided into rapid prototyping (RP) and rapid tooling (RT) by Pham and Dimov in 2003. RP was then further divided into the production of visual prototypes and functional prototypes and RT was divided into indirect tooling and direct tooling. A chart based on the classification scheme of Pham and Dimov is presented in Figure 1. [4] 


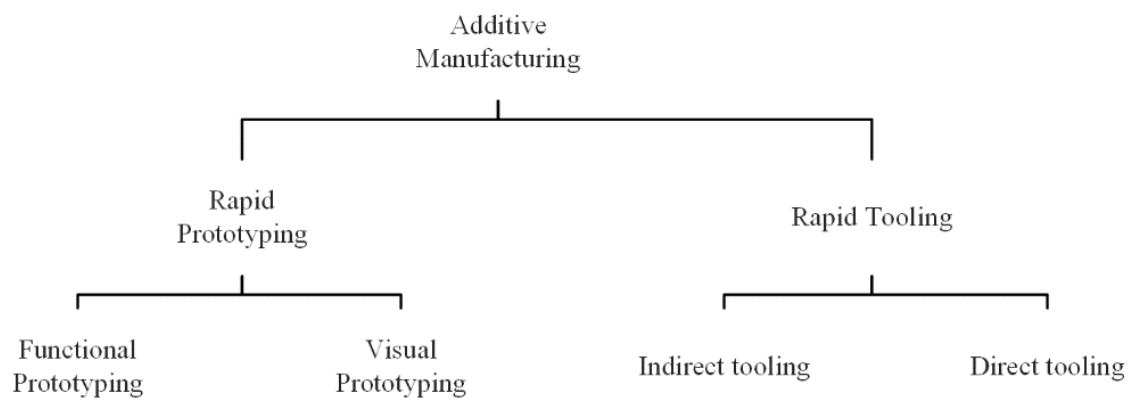

Fig. 1. The classification of AM usage based on the 2003 model of Pham and Dimov

Since the introduction of Pham and Dimov's classification, the quality, manufacturing speed and cost of AM technologies have improved considerably. This development has caused creating end-use products directly with AM to become viable, which has been demonstrated in many studies showing successful applications [5], [6], [7].

The ASTM standard defining the terminology of AM defines RP as "additive manufacturing of a design, often iterative, for form, fit, or functional testing, or combination thereof" and RT as "the use of additive manufacturing to make tools or tooling quickly, either directly, by making parts that serve as the actual tools or tooling components, such as mold inserts, or indirectly, by producing patterns that are, in turn, used in a secondary process to produce the actual tools". However, the ASTM standard makes no mention of a category of AM usage in which end-use parts are created. [8] A third category containing end-use components of AM has therefore been proposed but has not been officially sanctioned. The proposed names for the third category have been, among others, Rapid Manufacturing (RM), Direct Part Production and Direct Digital Manufacturing [9], [10], [11]. In this paper, we will refer to the third category as Rapid Manufacturing to keep in line with the original classification scheme.

The problem that was encountered during the early 2000 s is encountered again in RM. There are again so many applications of RM that it is difficult for new practitioners to evaluate its opportunities accurately. Based on the work of previous researchers, we have developed a classification scheme for RM using an approach similar to the one developed by Tuomi et al. to categorize medical applications of AM [12]. We propose to divide the RM category into three subcategories from the point of view of Design for Additive Manufacturing (DfAM) because the design of a component is actionable and affects the application directly. Another reason why the DfAM point of view is taken is that there is already a prolific community of researchers working in the sphere and their work can be used to bring additional value to the classification. The proposed subcategories are "Components designed for AM", "Components redesigned for AM," and "Components not designed for AM". The original RP/RT classification augmented with the proposed RM classification is presented in Figure 2. The reasoning behind the classification scheme, the description of the categories and an example of each are provided in the following section.

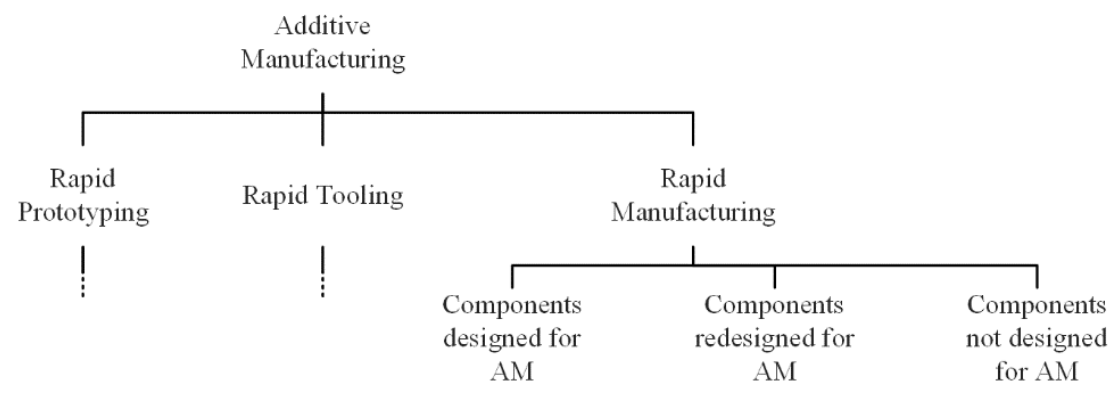

Fig. 2. The classification system of AM applications augmented with RM

\section{Definition of subcategories of rapid manufacturing from the point of view of DfAM}

There has been a growing interest in DfAM in recent years resulting in a large amount of literature being published. The key aspects introduced in those works are used to create the classification system presented. Klahn et al. describe two very relevant aspects of DfAM, which are the manufacturing driven and the function driven design strategies [11]. According to the authors, the manufacturing driven design strategy is used when the component is intended to be cheaper or faster to produce with AM than with traditional manufacturing technologies, while the function driven strategy is used when the component has features that can only be created with AM.

Laverne et al. give a description of two design approaches for AM: opportunistic and restrictive. The opportunistic design stage incorporates the advantages brought by AM, while the restrictive design stage changes the component to ensure that it is producible via AM [13]. 
There is an abundant amount of literature on the restrictive design of AM in peer-reviewed research and commercial actor documentation [14], [15], [16]. However, there is far less literature regarding opportunistic design [17], [18]. Ideally, this information is taken into account already at the beginning of the entire design chain and not only at the end during the restrictive design phase [19]. This is especially true for metal AM because the choice of material and orientation have a decisive effect on the outcome [20], [21]. For example, the design restrictions for aluminium are far more lenient than the ones for stainless steel. Although it is highly beneficial, considering the capabilities and restrictions of the AM technology the component is manufactured with is a challenging task, as the designer has to be intimately familiar with the AM technology if he wants to design all features according to its strengths and weaknesses.

Ponche et al. describe a "global" and a "partial" approach to DfAM. In the global approach, components should be defined from the point of view of functional requirements and the technological manufacturing limitations should only be taken into account at the very end of the design process. In the partial approach, the component exists before AM is taken into consideration and therefore goes only through a part of the DfAM process. [22] By combining the described concepts, it is possible to create a workflow that can be used to create the categories necessary for the classification. The resulting generalized design workflow of AM end-use components is shown in Figure 3.

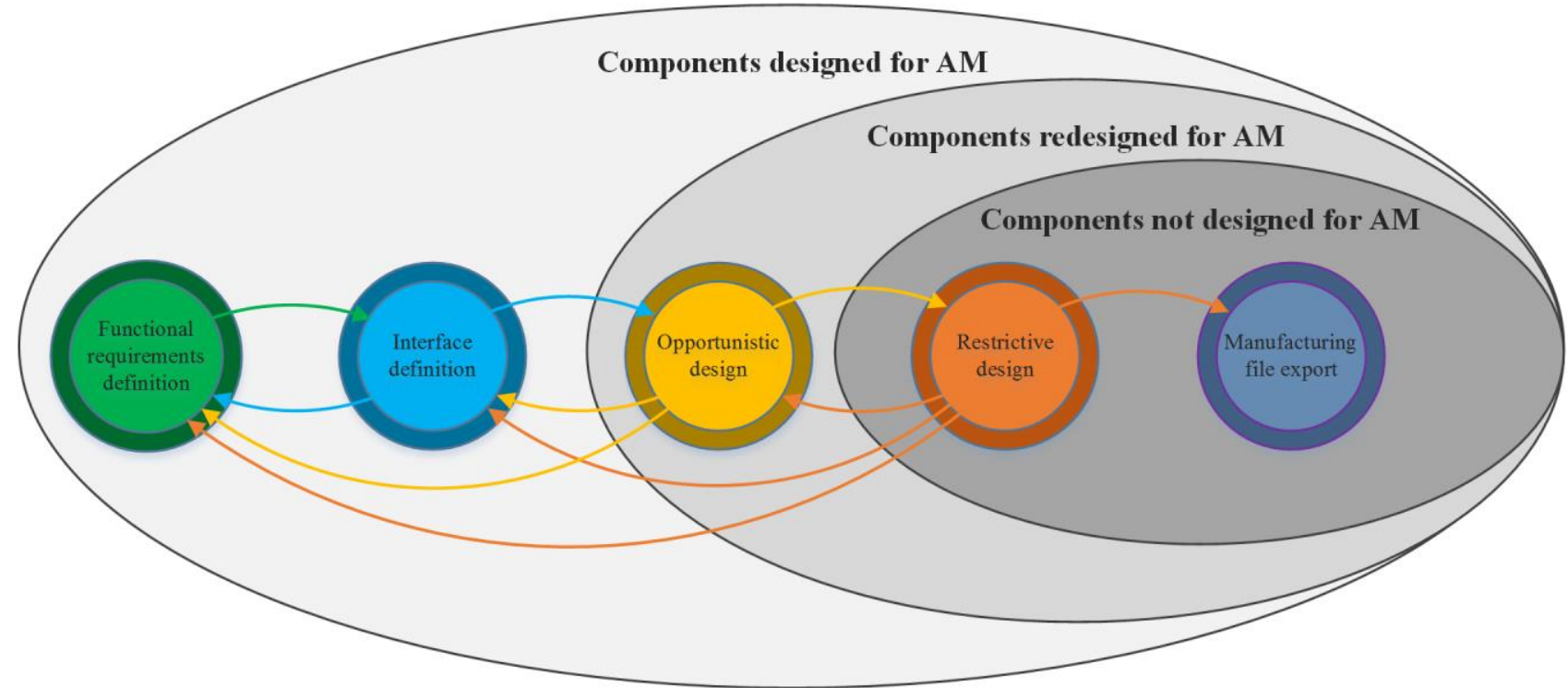

Fig. 3. A generalized design workflow of AM end-use components and the stages used by the three subcategories of $\mathrm{RM}$

Functional requirement definition is the stage of the design process in which the purpose and performance of the component are established. The central elements that enable the functionality are designed and dimensioned at this stage idealistically and without consideration of the restrictions of the manufacturing method. The functional requirement definition stage is followed by the definition of the interfaces that the component uses to connect to the system of which it is a part.

It is possible to design components by following the workflow in one direction, but to truly use the entire potential of DfAM, the recursive loops of the flowchart should be used. As a result, every stage of the design process should influence every stage that precedes it. Therefore, the definitions of the interface elements should affect the design of the functional elements of the component. Ideally, the functional requirement definition and interface definition should happen on the assembly level so that the design and dimensioning of all components are considered simultaneously.

Once the functionality and interfaces of the component are defined, the component is designed according to the benefits of AM in the opportunistic design stage, which includes, for example, topology optimization, computational fluid dynamics optimization, lattice structure inclusion, and designing internal channels with variable cross-sections [23], [24]. The opportunistic design stage is followed by restrictive design, in which the capabilities of the used AM machine are used to make sure that the design will be manufactured reliably. This includes such technical aspects of the design as minimum wall thicknesses and channel sizes, and maximum angles of overhanging features. The results of the restrictive design should affect the idealistically designed elements of the previous stages and result in a component that can be manufactured with the chosen AM machine. In the final stage, the design process is stopped by exporting the component design file for manufacturing purposes. Any given stage is commonly revisited multiple times and the rest of the workflow carried out after manufacturing the component to achieve improved results.

Inside the design workflow are the three proposed categories of end-use AM applications. The "Components designed for AM" category encompasses all the stages, while the other categories only use the design flow partially. Each stage of the described design process brings additional benefits, so the categories that encompass more stages gain more from being manufactured with AM. 
The functional driven and manufacturing driven strategies are also present in the design flow, as the components designed for the first category are usually function driven and the ones in the third category are manufacturing driven. While it is tempting to say that the "Components designed for AM" is the most valuable category from the point of view of AM use, it should be noted that all the categories have their place and include a variety of potential applications.

\subsection{Components designed for AM}

Components designed directly for AM are used commonly in high-tech applications and increasingly in more cost sensitive applications as the cost of AM decreases and the understanding of design opportunities in AM increases. The benefit of the components in this category is primarily new functionality achieved through manufacturing designs that are not possible to manufacture in any other method except AM. Components in this category require considering AM from the very beginning of the component definition process, including functional requirements and interface definition. An example for original design for AM is shown in Figure 4, representing an auger-extruder for UV-sensitive biomaterials. In this example, functional requirements such as the torque of the auger and design dimensions are not related to an existing component, but defined from the beginning by directly considering AM as the sole manufacturing method to be applied.

From a functional perspective, the extruder should be able to push UV-curable biomaterial through a robust small nozzle (diameter of approximately $1 \mathrm{~mm}$ ) to print precisely, and to cure each layer continuously, uniformly distributed and with high intensities if demanded. Additionally, there should be an accurate start/stop-functionality in order to extrude only during the time when new material for the printed components is needed. Thus, an auger was chosen to be a solution to fulfil functional extrusion requirements, modified with 4 UV-LEDs, which are attached circularly. To prevent material leakage on top of the auger, a cylinder with minimal clearance was added to the auger. In order to prevent nozzle damage while printing, the shell of the nozzle was reinforced by adding more material to it.

In the next step, required interfaces were considered, which are defined by the nozzle diameter of the extruder, the inlet diameter from the syringe pump $(3 \mathrm{~mm})$, attachments to the printer ( 2 holes for screws), a connection of the UVLEDs (solved by an outer channel) and a durable connection to the motor (realized with a press connection).

To print this component as fast as possible, wall thicknesses were designed as small as possible by maintaining all required functionalities. By choosing an optimal print orientation, the auger is printed directly inside the extruder, minimizing the number of components (part consolidation) and avoiding internal support structures, which cannot be removed in a post-processing step, when using stereolithography.
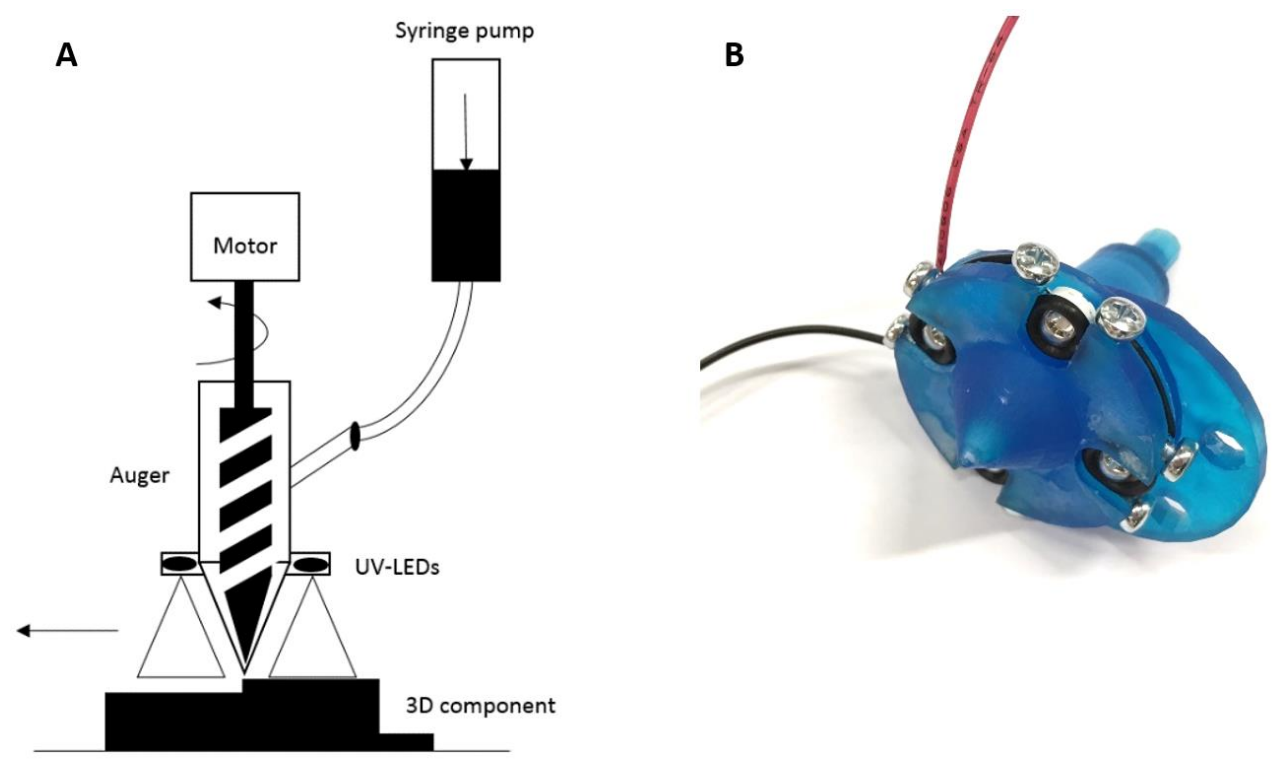

Fig. 4. Printed auger-extruder equipped with UV-LEDs (A) Scheme of the operating principle. The print material is pushed by a syringe pump and extruded steadily by the rotating auger. (B) Printed auger extruder head using stereolithography, which is equipped with 4 UV-LEDs to allow instant-curing of UV-sensitive materials

\subsection{Components redesigned for AM}

The functionality and interfaces are previously defined before AM is taken into consideration in components redesigned for AM. Therefore, the design process of the second category starts at the opportunistic design stage. The benefits of the category are primarily improved performance and reduced weight of components. The redesign approach requires some reverse engineering, because the important requirements of the components have to be acquired from the part itself, as this information is not always separately available, before any optimization can take place [25]. 
The second category is currently the most common one for multiple reasons. First, it is easy for companies to take a product from their own catalogue and redesign it to show the potential of AM. Second, the improvements brought by AM in an industrial environment are relatively simple to demonstrate when comparing the AM component to a part that was previously in real use. Third, keeping the interfaces identical to the original component is a desired quality among the companies because they would otherwise need to redesign the assemblies that include the component. Figure 5 demonstrates a typical case of a hydraulic system redesign from subtractive manufacturing to AM by importing the CAD file of the original component (a), analysis of interfaces and performance (b), opportunistic design of the flow channels (c), topology optimization (d), and triangulation of the final design (e).

(a)

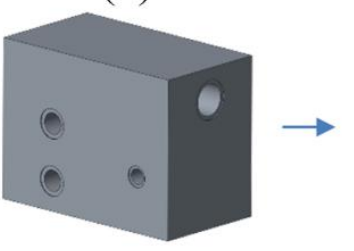

(b)

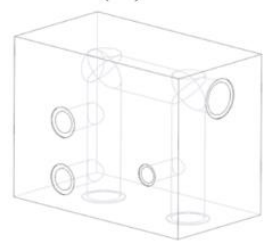

(c)

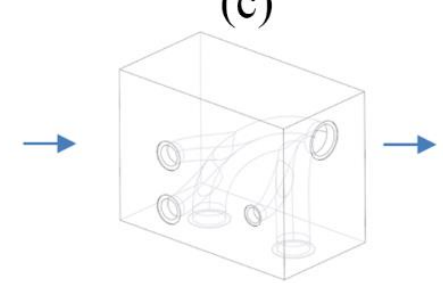

(d)

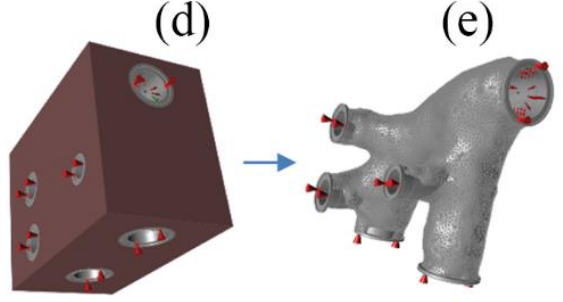

Fig. 5. The redesign procedure of a hydraulic block originally designed for subtractive manufacturing

\subsection{Components not designed for AM}

Components not designed for AM can nevertheless be useful to manufacture with AM under certain circumstances. According to Klahn, the manufacturing driven design strategy primarily takes into account the digital aspect of AM. In this strategy, the component could be manufactured with other methods, but it is faster or more economical to use AM [26]. The benefit of speed and cost comes primarily from the organizational facets of AM, such as being able to manufacture the component without moulds or significant set-up time. The concept of additively manufacturing spare parts that are no longer available through conventional channels takes advantage primarily of this category [27], [28]. The only design phase related to components not designed for AM is restrictive design to make the component possible to manufacture with AM. Figure 6 presents a simple electronics enclosure designed to be manufactured with plastic injection moulding onto which restrictive design was applied. In this case, the restrictions imposed by the AM process were that the walls and the slits at the top of the enclosure were too thin to manufacture. Therefore, the wall thickness of the enclosure had to be slightly increased and the slits on top of the enclosure had to be made wider and subsequently decreased in number to ensure a successful manufacturing process. The changes made to the design were necessary to make it possible to manufacture but did not affect its functionality or performance.
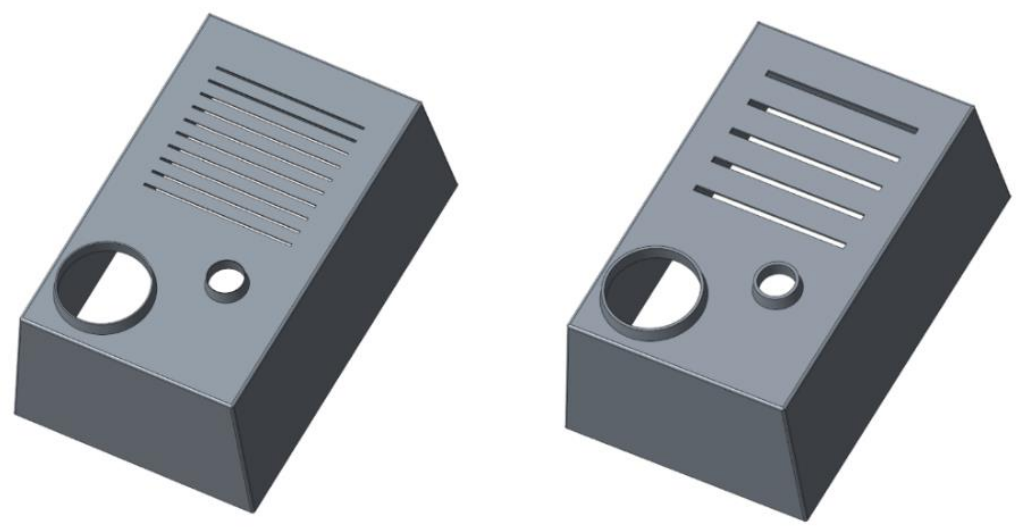

Fig. 6. An electronics enclosure designed for injection moulding on the left and after restrictive design on the right

\section{Future work and limitations}

It should be noted that there are other possible classifications of the subcategories of RM and the one presented in this article is particularly relevant for gaining a better understanding of the available opportunities. The categories of the presented classifications are demonstrated with single case studies in this article. Although this method is meant to present the available design approaches of each category with tangible examples, it is quite limited and does not represent all their characteristics. Therefore, a more comprehensive study investigating and demonstrating each category should be conducted. 
The workflow presented in Figure 3 comprises only the digital stage of component design. To use the workflow in real applications, the designs should also be subjected to economic and performance evaluation. In addition, the workflow would be more helpful to new practitioners if the links to lower levels of the design steps, such as the limitations of specific AM technologies, were clearer.

While each of the categories is individually well defined, the difference between "Components designed for AM" and "Components redesigned for AM" can be ambiguous especially when considering assemblies. Future work concerning the classification system should concentrate on evaluating the boundaries between the three categories. Another avenue of further research has to do with the validation of the utility of the classification. This requires, for example, introducing the classification in the curriculum of an AM centric university course, or performing a focus group study with professionals in the field of industrial design.

\section{Conclusion}

A product design oriented classification system was developed for end-use applications of AM. The classification system is based on a DfAM process flow constructed from a collection of previous works of several researchers in the field. The classification divides the end-use applications of AM according to how many of the design steps apply to them. The category that all the stages apply to, and the one which consequently benefits the most from DfAM, is "Components designed for AM". The second category comprises components that use the DfAM process only from the opportunistic design stage onwards and is called "Components redesigned for AM". Finally, "Components not designed for AM" implements only the restrictive design stage of the process flow. The classification system should be of considerable help to engineers looking for end-use applications of AM in industrial settings.

The machinery of AM and its possible applications are improving at a pace that ensures that the concept of DfAM is in a state of constant evolution. Therefore, we encourage fellow researchers and practitioners to augment and update the proposed classification scheme.

\section{References}

[1] Dalgarno, K. W. (2001). Production grade tooling via layer manufacture. Rapid Prototyping Journal, 7(4), pp. 203206. https://doi.org/10.1108/EUM0000000005752

[2] Wai, H. W. (2001). RP in art and conceptual design. Rapid Prototyping Journal, 7(4), pp, $217-219$. https://doi.org/10.1108/EUM0000000005895

[3] Tang, Y., Fuh, J. Y. H., Lu, L., Wong, Y. S., Loh, H. T., \& Gupta, M. (2002). Formation of electrical discharge machining electrode via laser cladding. Rapid Prototyping Journal, 8(5), pp. $315-319$. https://doi.org/10.1108/13552540210451787

[4] Pham, D. T., \& Dimov, S. S. (2003). Rapid prototyping and rapid tooling - the key enablers for rapid manufacturing. Proceedings of the Institution of Mechanical Engineers Part C-Journal of Mechanical Engineering Science, 217(1), pp. 1-23. https://doi.org/10.1243/095440603762554569

[5] Prada, J. G., Cazon, A., Carda, J., \& Aseguinolaza, A. (2016). Direct digital manufacturing of an accelerator pedal for a Formula Student racing car. Rapid Prototyping Journal, 22(2), pp. 311-321. https://doi.org/10.1108/RPJ-052014-0065

[6] Meisel, N., Woods, M. R., Simpson, T. W., \& Dickman, C. J. (2017). Redesigning a Reaction Control Thruster for Metal-Based Additive Manufacturing: A Case Study in Design for Additive Manufacturing. Journal of Mechanical Design, pp. 1-8. https://doi.org/10.1115/1.4037250

[7] Chekurov, S., \& Lantela, T. (2017). Selective Laser Melted Digital Hydraulic Valve System. 3D Printing and Additive Manufacturing, 4(4), pp. 215-221. https://doi.org/10.1089/3dp.2017.0014

[8] ASTM International. (2013). F2792-12a - Standard Terminology for Additive Manufacturing Technologies. Rapid Manufacturing Association, pp. 10-12. https://doi.org/10.1520/F2792-12A.2

[9] Mellor, S., Hao, L., \& Zhang, D. (2014). Additive manufacturing: A framework for implementation. International Journal of Production Economics, pp. 149, 194-201.

[10] Chen, D., Heyer, S., Ibbotson, S., Salonitis, K., Steingrímsson, J. G., \& Thiede, S. (2015). Direct digital manufacturing: Definition, evolution, and sustainability implications. Journal of Cleaner Production, 107, pp. 615625. https://doi.org/10.1016/j.jclepro.2015.05.009

[11] Klahn, C., Leutenecker, B., \& Meboldt, M. (2015). Design strategies for the process of additive manufacturing. Procedia CIRP, 36, pp. 230-235. https://doi.org/10.1016/j.procir.2015.01.082

[12] Tuomi, J., Paloheimo, K. S., Vehviläinen, J., Björkstrand, R., Salmi, M., Huotilainen, E., ... Mäkitie, A. A. (2014). A novel classification and online platform for planning and documentation of medical applications of additive manufacturing. Surgical Innovation, 21(6), pp. 553-559. https://doi.org/10.1177/1553350614524838

[13] Laverne, F., Segonds, F., Anwer, N., \& Le Coq, M. (2015). Assembly Based Methods to Support Product Innovation in Design for Additive Manufacturing: An Exploratory Case Study. Journal of Mechanical Design, 137(12), pp. 121701. https://doi.org/10.1115/1.4031589 
[14] Meisel, N., \& Williams, C. (2015). An Investigation of Key Design for Additive Manufacturing Constraints in Multimaterial Three-Dimensional Printing. Journal of Mechanical Design, 137(11), pp. 111406. https://doi.org/10.1115/1.4030991

[15] Adam, G. A. O., \& Zimmer, D. (2015). On design for additive manufacturing: Evaluating geometrical limitations. Rapid Prototyping Journal, 21(6), pp. 662-670. https://doi.org/10.1108/RPJ-06-2013-0060

[16] Dinar, M., \& Rosen, D. W. (2017). A Design for Additive Manufacturing Ontology. Journal of Computing and Information Science in Engineering, 17(2), pp. 21013. https://doi.org/10.1115/1.4035787

[17] Kranz, J., Herzog, D., \& Emmelmann, C. (2015). Design guidelines for laser additive manufacturing of lightweight structures in TiAl6V4. Journal of Laser Applications, 27(S1), pp. S14001. https://doi.org/10.2351/1.4885235

[18] Salonitis, K. (2016). Design for additive manufacturing based on the axiomatic design method. International Journal of Advanced Manufacturing Technology, 87(1-4), pp. 989-996. https://doi.org/10.1007/s00170-016-8540-5

[19] Schmelzle, J., Kline, E. V., Dickman, C. J., Reutzel, E. W., Jones, G., \& Simpson, T. W. (2015). (Re)Designing for Part Consolidation: Understanding the Challenges of Metal Additive Manufacturing. Journal of Mechanical Design, 137(11), pp. 1-12. https://doi.org/10.1115/1.4031156

[20] Kretzschmar, N., Ituarte, I. F., \& Partanen, J. (2018). A decision support system for the validation of metal powder bed-based additive manufacturing applications. International Journal of Advanced Manufacturing Technology, pp. 1-12. https://doi.org/10.1007/s00170-018-1676-8

[21] Nozar, M., Zetkova, I., Hanzl, P., \& Dana, M. (2017). A Customer's View on Key Aspects of Metal Additive Manufacturing, Proceedings of the 28th DAAAM International Symposium, pp. 0957-0966, B. Katalinic (Ed.), Published by DAAAM International, ISBN 978-3-9027341-11-2, ISSN 1726-9679, Vienna, Austria https://doi.org/10.2507/28th.daaam.proceedings.133

[22] Ponche, R., Kerbrat, O., Mognol, P., \& Hascoet, J. Y. (2014). A novel methodology of design for Additive Manufacturing applied to Additive Laser Manufacturing process. Robotics and Computer-Integrated Manufacturing, 30(4), pp. 389-398. https://doi.org/10.1016/j.rcim.2013.12.001

[23] Ramadani, R., Belsak, A., Kegl, M., Predan, J., \& Pehan, S. (2018). Topology optimization based design of lightweight and low vibration gear bodies. International Journal of Simulation Modelling, 17(1), pp. 92-104.

[24] Hanzl, P., Zetková, I., \& Dana, M. (2017). A Comparison of Lattice Structures in Metal Additive Manufacturing, Proceedings of the 28th DAAAM International Symposium, pp. 0481-0485, B. Katalinic (Ed.), Published by DAAAM International, ISBN 978-3-9027341-11-2, ISSN 1726-9679, Vienna, Austria https://doi.org/10.2507/28th.daaam.proceedings.067

[25] Orquéra, M., Campocasso, S., \& Millet, D. (2017). Design for additive manufacturing method for a mechanical system downsizing. Procedia CIRP, 60(December), pp. 223-228. https://doi.org/10.1016/j.procir.2017.02.011

[26] Klahn, C., Leutenecker, B., \& Meboldt, M. (2014). Design for additive manufacturing - Supporting the substitution of components in series products. Procedia CIRP, 21, pp. 138-143. https://doi.org/10.1016/j.procir.2014.03.145

[27] Khajavi, S. H., Partanen, J., \& Holmström, J. (2014). Additive manufacturing in the spare parts supply chain. Computers in Industry, 65(February 2016), pp. 50-63. https://doi.org/10.1016/j.compind.2013.07.008

[28] Chekurov, S., \& Salmi, M. (2017). Additive Manufacturing in Offsite Repair of Consumer Electronics. Physics Procedia, 89, pp. 23-30. https://doi.org/10.1016/j.phpro.2017.08.009 